\title{
Correction to: Long read sequencing reveals novel isoforms and insights into splicing regulation during cell state changes
}

David J. Wright', Nicola A. L. Hall2,3, Naomi Irish', Angela L. Man', Will Glynn'1, Arne Mould 2,3, Alejandro De Los Angeles ${ }^{2,3}$, Emily Angiolini ${ }^{1}$, David Swarbreck' ${ }^{1}$ Karim Gharbi ${ }^{1}$, Elizabeth M. Tunbridge ${ }^{2,3}$ and Wilfried Haerty ${ }^{1 *}$

\section{Correction to: BMC Genomics 23, 42 (2022)}

https://doi.org/10.1186/s12864-021-08261-2

Following publication of the original article [1], it was that there was an error in Fig. 4. There was an overlaid panel in the center of the image. The correct Fig. 4 is provided in this Correction and the original article [1] has been updated.

\footnotetext{
Author details

${ }^{1}$ Earlham Institute, Norwich Research Park, Norfolk NR4 7UZ, UK. ${ }^{2}$ Department of Psychiatry, Medical Sciences Division, University of Oxford, Oxfordshire OX3 3JX, UK. ${ }^{3}$ Oxford Health, NHS Foundation Trust, Oxford, Oxfordshire OX3 7JX, UK.
}

Published online: 25 January 2022

\section{Reference}

1. Wright DJ, Hall NAL, Irish N, et al. Long read sequencing reveals novel isoforms and insights into splicing regulation during cell state changes. BMC Genomics. 2022;23:42. https://doi.org/10.1186/s12864-021-08261-2. 


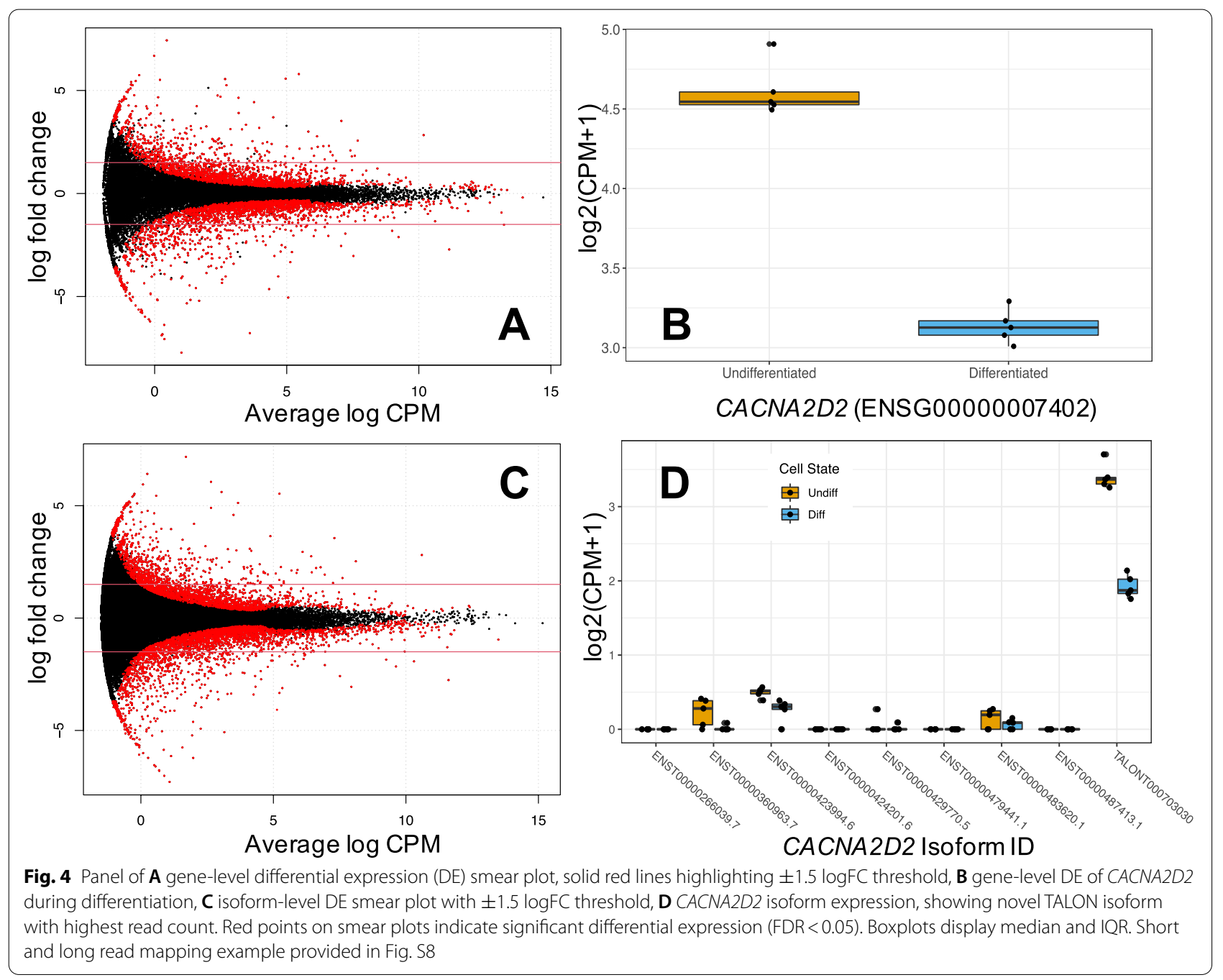

